\title{
THE AGRICULTURE APPLICATION PROSPECT OF IGIS
}

\author{
Xiaoyang Cui ${ }^{1}$, Kaimeng Sun ${ }^{1}$, Dingcun Yan ${ }^{1}$, Yeping Zhu ${ }^{1, *}$ \\ ${ }^{\prime}$ Agricultural Information Institute, Chinese Academy of Agricultural Sciences, Beijing, \\ China, 100081 \\ * Corresponding author, Address: Library 311, Agricultural Information Institute, Chinese \\ Academy of Agricultural Sciences, No. 12 Zhongguancun South Street, Beijing, 100081, P. R. \\ China, Tel: +86-10-68919652-2342, Fax: +86-10-68975172, Email: zhuyp@mail.caas.net.cn
}

\begin{abstract}
The article expatiates the conception, definition and application status of GIS and IGIS and discusses the two systems to form agriculture application IGIS combined with three GIS development tools including Arcinfo, MapInfo and SuperMap.
\end{abstract}

Keywords: GIS, IGIS, SuperMap

\section{INTRODUCTION}

We discuss GIS, AI and IGIS as followings:

\subsection{Geography Information System (GIS)}

\subsubsection{Conception}

It is a computer application software system with those strong functions to collect, store, edit, manage, describe and analyze space data. Because of it's powerful management and analysis of space data and drawing ability, It is used widely to the research and application of description and expression of space elements and correlative relations.

Cui, X., Sun, K., Yan, D. and Zhu, Y., 2008, in IFIP International Federation for Information Processing, Volume 259; Computer and Computing Technologies in Agriculture, Vol. 2; Daoliang Li; (Boston: Springer), pp. 1223-1230. 
GIS is the integration of computer science, geography, measurement science and cartology. It is difficult to give a definite definition. Because of it's wide coverage, it can be given different definitions from different angels. It can usually definite GIS from four different ways. First we definite from function, GIS is a system to collect, store, check, handle, analyze and show geography data. Second we definite from application, we can divide GIS into different application system according to the different GIS application fields such as soil information system, city information system, layout information system and space decision support system etc. (Fan Hong, 2002) Third we can definite from toolbox, GIS is a collection of tools to collect, store, query, change and show space data. The definition emphasizes the tool to handle geography data provided by GIS. Finally we can definite from database, GIS is such a database system whose data has space order and provide an operation collection to deal with those data to answer the query of space entity in database Fig. 1.

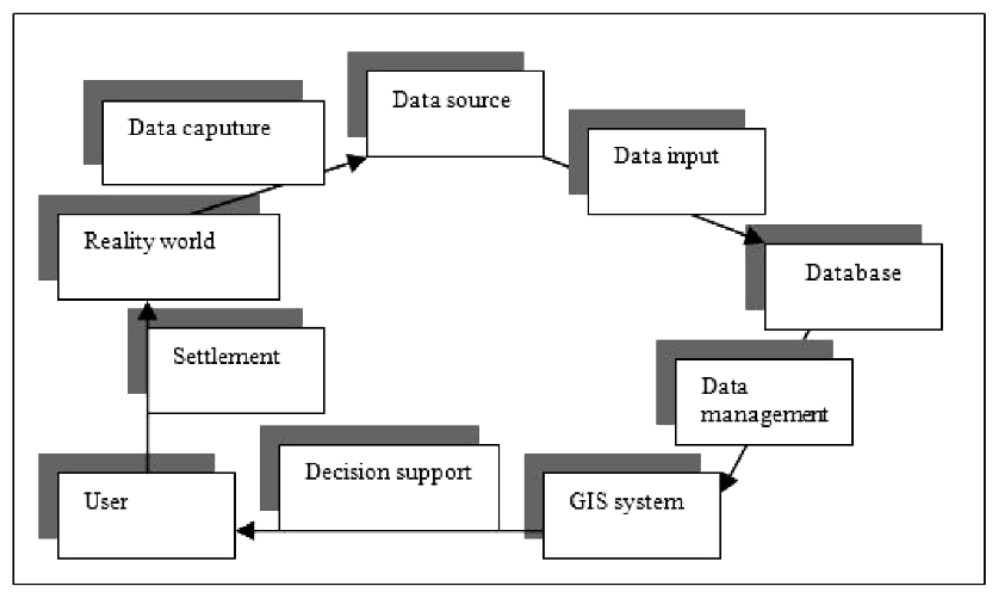

Fig. 1. GIS function structure diagram

\subsubsection{Application trend}

The current application trends of GIS represent is as following aspects (Lv Xin, 2002):
(1) Integration
(2) Intelligence
(3) Modularization
(4) Network
(5) Subassembly
(6) Standardization 


\subsection{AI (Artificial Intelligence)}

\subsubsection{Definition}

It is an important research field of computer science. Professor Nilsson of AI research center of Stanford University thinks: "AI is a science about knowledge - a science about how to express knowledge and how to obtain and use knowledge". (Sun Chengming, 2004) Professor Winston of MIT University indicates: "AI is to research how to use computer to do the intelligent work which can be done only by man in the past". Those definitions reflect the basic thoughts and scale of AI study.

\subsubsection{Applications}

Currently, the main application fields of AI include:

(1) Expert System. The system stimulates the procedure to solve a sophisticated problem which can be solved only by mankind experts.

(2) Repository. To store, process and manage the mankind's knowledge and to dispose and apply the knowledge according to the need.

(3) Decision support system. To process assistant decision of mankind's activity by means of stimulation and reasoning through model and knowledge (Hu Cun, 1998).

(4) Natural language comprehension. To comprehend the mankind's nature language to realize the direct communication between mankind and computer to promote the broad application of computer.

(5) Intelligent robot. It is the robot which has feeling, identification and policy decision function.

(6) Mode recognition. To stimulate the functions of hearing and seeing of mankind to identify the sound, image, scene and character.

(7) Auto program design. To implement the automation of program design with the computer to achieve the program's validation and integration.

\subsection{Intelligent Geography Information System (IGIS)}

IGIS should be studied firstly from space analysis intelligence, artificial neural network and inheritance arithmetic put a doable way to space information intelligence.

\subsubsection{The status quo of IGIS}

Currently, GIS is used successfully to the fields including resource management, establishment management, city and district layout, population 
and commerce management, traffic and transportation. The traditional GIS have strong data input, storage, search and display ability. With the day and day going deep into those fields's application, we encounter many things of experiment of some determinative questions to make traditional functions of GIS unable to satisfy the demand; this requires combining GIS with the very popular AI to exert each merit to solve the problems perfectly. The nineties last century, many domestic and abroad scholars begin to study the IGIS and obtain many successful applications. The southern Africa scholar Veldic Vado and Han City university Chulmin Jun apply independently to the city's ground address selection with the integration of Expert System and Geography Information System and study the integration method of GIS and ES, GIS and math model. Professor David Lanter of California University studied particularly the insufficiency existing in GIS, and import AI into GIS to reinforce GIS to make it more practical and flesh. The scholar Leonid Stoimenov of Jugoslavia develops the alarm prediction system based on repository and GIS (Wu Xincai, 2000).

Moreover, there are many researches applying to the intelligent study of GIS and this makes many productions. Domestically, those studies are just in primary stage and many scholars publish some articles to discuss the integration problem of AI and GIS. In a case of electrify network distribution, transportation and trouble diagnose, the Orient Electron co., ltd combined the Expert System and Geography Information System to apply. Zhao-Shi peng of Northeast Normal University applies the integration technology of GIS and ES in the evaluation of mud and stone flow. Wang-Shi Chen, MaSheng Zhong of Jilin University have applied to combine the GIS and ES to predict the mine production and developed a set of unique theory for many years.

We can conclude from above statement that IGIS research has a full application coverage and vast prospect research field. But it's research is still in primary stage Fig. 2.

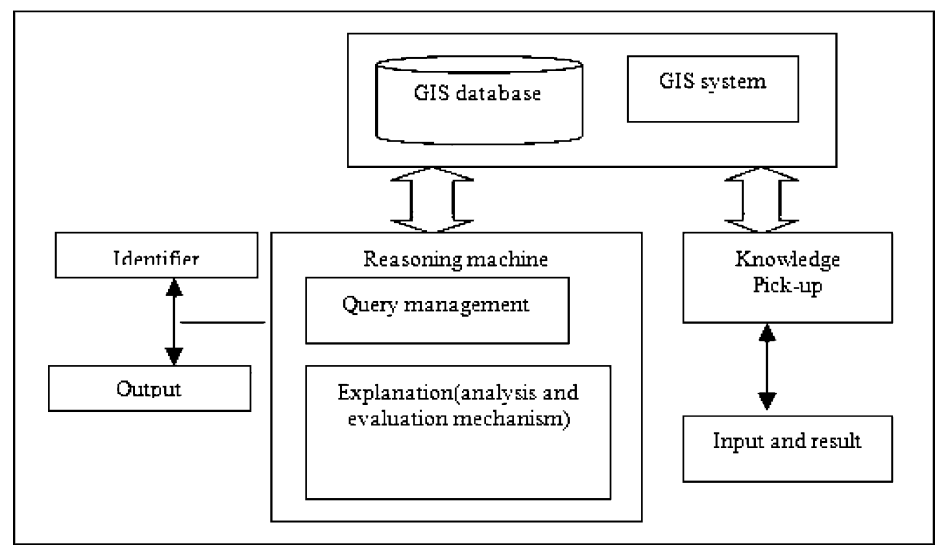

Fig. 2. A IGIS system prototype 


\section{ARCINFO, MAPINFO AND SUPERMAP}

\subsection{Arcinfo}

It is developed by American ESRI (American Environment System Research Institute), It is a professional GIS (geography information system) platform software with abundant function and includes the following diversified and advanced functions:

(1) The function to input and edit data. We can acquire data from digital instrument, graph scanner, graph transportation to edit graph and property.

(2) Data transportation and integration. We can transform those standard data format and support the relation database which accords with SQL standard.

(3) Basic GIS functions. Map projection and projection transformation, data maintenance and management, cushion and fold analysis.

(4) Space data and property query to show corresponding graph including grid graph display and management.

(5) Geography data management. We can manage a large distributed database using info database or ArcSDE.

(6) It provides the interface design tool and the system second development tool. It uses aml language, MO module base and VC, VB which support industry standard as main development tools.

(7) Data output. It provides functions to make high quality digital map and report forms.

(8) It supports edition management and business transaction.

\subsection{MapInfo}

It is desktop geography information software of American MapInfo Corporation, It is a desktop solution scheme to visualize data and map information.

\subsection{Supermap}

SuperMap GIS is a new generation large geography information system platform developed by Beijing SuperMap Geography Information Technology co., ltd depending on the technology advantage of CAS and based on technology innovation to fulfill different kind of customer's need of all trades. SuperMap GIS 5.2 series productions are the newest edition of 
SuperMap GIS. It supports the incorporation of storage structure, usage and management of space data and statistics subject, and supports the application and development of multi layers structure based on B/S structure (Xun Fanlun, 2002).

\subsubsection{Database engine and module structure}

(1) SuperMap SDX $+5.2-$ Space database engine which supports huge space data management.

(2) SuperMap Objects 5.2 -Full module GIS development platform suitable to large professional application system.

(3) SuperMap IS .NET 5.2 - Internet GIS development platform used to build large network GIS service.

(4) eSuperMap 5.2 -Embeded GIS development platform suitable to moving terminal device.

(5) SuperMap Deskpro 5.2 —Popular desktop GIS software used to geography space data disposal and analysis model.

(6) SuperMap Express 5.2 -Desktop GIS software used to edit and handle geography space data.

(7) SuperMap Viewer 5.2 - Tool software used to browse geography space data(Zhao Peng, 2003).

\section{AGRICULTURE APPLICATION OF IGIS}

There are those agriculture applications combined with the aforesaid IGIS secondly developed by GIS development platform at present:

(1) Wild moving data collection system eFieldSurvey based on the palm computer.

(2) Agriculture climate district-division geography information system.

(3) Heilongjiang forest fire information and fire loss evaluation system.

(4) Fangshan forest industry basic space database management system.

(5) Forest fireproofing and resource geography information system.

(6) Extract agriculture farm geography information system.

I will give a brief introduction to the exact agriculture farm geography information system:

The system uses IGIS, GPS and intelligent agriculture technology to adjust and control agriculture production information management and farm devotion to increase benefit, avoid resource waste and reduce environment pollution. The farm geography information system of the Geography Institute of CAS is developed cooperatively by the Geography Institute of 
CAS and Beijing SuperMap Geography Information Technology co., ltd. The system adopted full module GIS software SuperMap Objects as development platform using its characters easy to integrate with other systems and development advantage. Combining farm GIS and farm ration computation module system, it provide a strong tool for quantificational study farm ecology system and the improvement of farm unit production (Smith T R, 2004).

(7) Corn ecology which is suitable to district division and, responding corn seed selection.

(8) Ascertain of the match-series scheme suitable to every cooked area.

(9) Prediction of the yield.

(10) Forecast the agriculture nature disaster.

\section{SUMMARIZATION}

GIS is developed rapidly, It provides a good basic platform for our agriculture science and research worker to develop agriculture intelligent geography information system (IGIS), The article gives a detailed discussion to the GIS's concept, definition and development trend and discusses the agriculture application of GIS, In our country, though the research and application make some progress, it is basically in the primary stage. I wish the article have an active function to promote the research, development, popularization and application of IGIS to a deep domain (Robinson V B, 2003).

\section{ACKNOWLEDGEMENTS}

The article is sponsored by the Center-level Commonweal-Quality Science and Research Academy and Institute Basic Science and Research Operation Fee Special Item Capital Item-the Country Science and Technology Support Item (No. 2006BAD10A06).

\section{REFERENCES}

2004. Weather Publishing Company, 53-66

Fan hong, Zhan Xiaoguo. 2002. Arcinfo application and development http://www.supermap.cn/gb/application/0ssgl/JTGPS/minhangjj/

Hu Cun. 1998. GIS's application in agriculture information management and district-division. Tianjin Agriculture Science, 4, 34-37

Lv Xin. 2002. Geography information system and its application in agriculture 
M. Wooldridge, N. Jennings, and D. Kinny. 2000. The Gaia Methodology for Agent-Oriented Analysis and Design. Journal of Autonomous Agents and Multi-Agent Systems, 3(3).

Robinson V B. 2003. Expert systems and geographical information system. Review and Prospects, Journal of Surveying Engineering, 6, 92-95

Smith T R. 2004. A knowledge-based geographical information system. International Journal of Geographical Information Systems, 1, 116-118

Sun Chengming. 2004. The agriculture application and evolvement of geography information system [J], Shanghai Agriculture Transaction, 3, 18-21, technology (emended edition). Wuhan University Publishing Company, 97-113

The brief introduction of civil aviation economy information GIS application system.

Wu Xincai, Guo Linlin. 2000. The development status and prospect of geography information system. Computer Engineering and Application, 4, 8-9

Xun Fanlun. 2002. Artifical intelligence and computer's application in agriculture modernization. Agriculture Modernization Research, 5,123-126

Zhao Peng. 2003. Intelligent geography information system's development and research. Computer Development, 2, 37-40 